\title{
Renditeorientierte Anlage mit garantiertem Zins
}

\author{
Helvetia Swiss Trend, die indexgebundene Lebensversicherung
}

\section{Die trendige Kombination}

Helvetia Swiss Trend ist eine Lebensversicherung, die an den Trend des Aktienindexes SMI gekoppelt ist. Steigt der SMI, so steigt auch Ihre Anlage. Sinkt jedoch der SMI, so wird Ihr Kapital unabhängig vom Börsenverlauf trotzdem garantiert verzinst.

Die Helvetia möchte mit diesem Produkt an die Erfolgsgeschichte der neunziger Jahre anknüpfen. Damals wurden drei Tranchen dieses Produktes lanciert, die trotz Börsencrash zu Beginn des neuen Jahrtausends eine Rendite von mindestens $6 \%$ pro Jahr erwirtschaftet haben.

\section{Ihre Vorteile auf einen Blick}

- Attraktive Renditeaussichten dank Partizipation am Trend des Swiss Market Index SMI

- Schutz vor Kurseinbrüchen

- Garantierte Mindestverzinsung des Sparkapitals

- Steuerfreie Auszahlung, sofern die Bedingungen der eidg. Steuerverwaltung erfüllt sind (Auszahlung nach 60. Geburtstag, Abschluss vor 66. Geburtstag, Dauer mind. 5 Jahre)

\section{Erfolgsgeschichte}

Bereits mehrere Helvetia-Swiss-Trend-Produkte wurden erfolgreich am Markt plaziert:

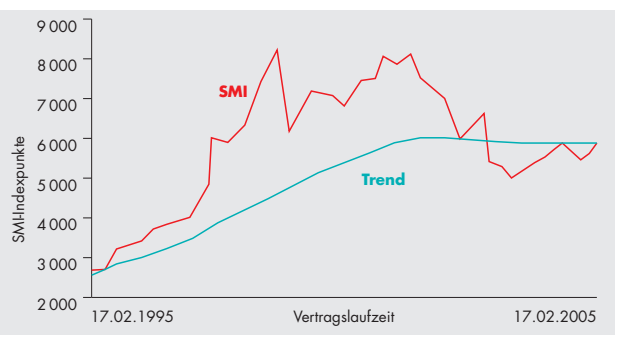

Beispiel: Patria Swiss Trend II erzielte eine Rendite von durchschnittlich $8,5 \%$ p. a.
Achtung

Zeichnungsfrist 9.7.-7.9.2007

Dieses Produkt ist nur tranchenweise verfügbar. Die Zeichnungsfrist läuft vom 9. Juli bis zum 7. September 2007. Eine weitere Tranche ist im Moment nicht beabsichtigt.

Profitieren auch Sie von dieser Gelegenheit, und bestellen Sie noch heute eine persönliche Offerte mit dem untenstehenden Talon.

\section{helvetia A}

\section{Antworttalon}

Vorname / Name

Adresse

PLZ / Ort

Geburtsdatum

Telefon privat/Geschäft

Beste Zeit für einen Anruf

E-Mail-Adresse

Bitte senden Sie mir eine Offerte für Helvetia Swiss Trend. Anlagesumme: Fr.

Ich wünsche eine persönliche Beratung.

Bitte rufen Sie mich an.

Ich interessiere mich für:

\footnotetext{
Kapitalanlage

Pensionskasse BVG

Säule $3 a$

Berufshaftpflichtversicherung

Vorzeitige Pensionierung
} 